\title{
A Survey of the Awareness and Attitudes of an Adult Population towards Clinical Hypnosis
}

\author{
Varun V. Bansal ${ }^{1}$, Swaksh P. Nemani ${ }^{2}$, Munira A. Hirkani ${ }^{3}$. Anuya A. Natu ${ }^{4}$, Avani A. Natu', \\ Urmi G. Parmar \\ 1,2,4,5 Undergraduate Medical Student, \\ ${ }^{3}$ Associate Professor, Department of Physiology, \\ Seth G.S. Medical College KEM Hospital, Mumbai \\ Corresponding author: Varun V. Bansal \\ Email: mbbs160163@kem.edu
}

\begin{abstract}
Background: Clinical hypnosis has been used as a primary and a supplementary treatment modality for various diseases. We conducted a cross-sectional survey of 600 adults living in the state of Maharashtra, India, over two months to assess their awareness about and attitudes towards clinical hypnosis.

Methodology: Using a pre-validated questionnaire containing 26 items, we evaluated the awareness of the subjects in two principal domains- the practice of clinical hypnosis, and the therapeutic uses of clinical hypnosis. The aggregate of the correctly answered questions under these domains was designated as the awareness score for each subject. We assessed the attitudes and willingness of the subjects to accept clinical hypnosis under a separate domain, the attitudes. A separate set of questions addressed the experiences of subjects who had visited a hypnotherapist before.

Results: Although the study population had poor awareness about clinical hypnosis (Mean awareness score $=45.53 \%, \mathrm{SD}=18.61 \%), 82.5 \%$ of subjects had a positive attitude towards it. The awareness scores correlated positively with the attitude scores (chi-square $=48.561, p=0.000$ ). Four of the five subjects who had experienced clinical hypnosis found it beneficial for their respective indications, three of which would be willing to approach a hypnotherapist again and refer people to hypnotherapists.

Conclusion: Greater awareness about clinical hypnosis is associated with a positive attitude towards it. Hence, increasing the awareness of people regarding clinical hypnosis is likely to improve their attitude towards the same.
\end{abstract}

Keywords: Hypnosis, Hypnotherapy, Survey, Awareness, Attitude

[Paper received $-17^{\text {th }}$ July 2020, Peer review completed $-29^{\text {th }}$ August 2020, Accepted $-30^{\text {th }}$ August 2020]

\section{INTRODUCTION}

The world of medicine and health sciences has seen a surge in the global utilization and recognition of various treatment modalities over the last few decades. Many of these therapies are yet to be utilised on a wide scale. One such clinically relevant therapy is clinical hypnosis. The American Psychological Association defines hypnosis as "A state of consciousness involving focused attention and reduced peripheral awareness characterized by an enhanced capacity for response to suggestion" [1].

Hypnosis as a mode of therapy, referred to as "Hypnotherapy" and "Clinical hypnosis" is used to treat various diseases for which conventional therapy is often unsatisfactory, like irritable bowel syndrome [2]. In the prophylaxis and treatment of migraine and headaches, clinical hypnosis is found to be efficacious, relatively brief and cost-effective. In comparison with widely used medical treatments, it is virtually free of side effects and adverse reactions [3]. The use of clinical hypnosis instead of local anaesthesia in dental surgery is described in case reports [4]. However, clinical hypnosis is being routinely used as a complement rather than an alternative to modern, safe techniques of anaesthesia, primarily to minimize anxiety and stress. It has been shown to reduce pain, anxiety, and the consumption of analgesics and sedatives to a statistically significant extent in patients undergoing operations under local or regional anaesthesia [5]. It 
has also been implemented in psychotherapy for pain management, both chronic non-cancer and cancer pain [5-6].

Although hypnotherapy is a treatment modality with immense potential, misconceptions may bridle its widespread use. Palsson, Twist, \& Walker in their study found that receiving information about hypnosis from television, magazines, or stage hypnosis promoted misconceptions about clinical hypnosis, while credible sources such as health professionals and non-fiction books helped increase positive views of hypnosis as a therapy [7]. Some common myths regarding clinical hypnosis include that it is a passive state most commonly being likened to sleep, that hypnotic subjects show inevitable amnesia for what went on in hypnosis, people of strong will power cannot be hypnotised and that there are gender differences in hypnotisability [8]. People often believe that the subject is forced to reveal information or thoughts that one would not normally reveal, while in the state of hypnosis. There is a prevalent fear of handing complete control of themselves to the hypnotherapist and becoming robot-like and being made to do things against their will [9].

There is evidence that people prefer the hypnotherapist to be connected with a medical or psychological establishment, either through qualification or via referral. There is a clear perception that the hypnotherapist's skill is a factor in the success of clinical hypnosis [10]. When used by a person who is inexperienced or untrained, or a person uncaring in his relationship with the hypnotised subject, clinical hypnosis can cause psychopathological symptoms in the subject. The subject may experience anxiety or it may revoke an earlier trauma and enhance the related stress. In such scenarios, it is also known to precipitate brief psychotic episodes in subjects. The medical professionals who use hypnotic techniques must evaluate the patient's motivation to undergo clinical hypnosis, and their goals must be specific to their area of competence [11]. In India, clinical hypnosis is practised by a variety of professionals, some with doubtful qualifications. Hence, efforts to standardize its practice may make the modality more acceptable among people [12]. There is no overall picture regarding the views and experiences of clinical hypnosis amidst the general public in the existing literature. Hence, we conducted this survey to assess the awareness of the general population and their attitudes towards clinical hypnosis in our country and to establish whether the awareness influences the attitudes of the people.

\section{METHODOLOGY}

We carried out the cross-sectional, electronic survey over two months after approval by the Institutional Ethics Committee.

\section{Inclusion criteria:}

All the subjects included in the study were

1. Capable of reading and writing in English, Hindi, or Marathi

2. Adults (above the age of 18 years)

3. Living in the state of Maharashtra

\section{Study design and sample size:}

Based on a national survey conducted in the adult population of the United States, we considered the prevalence of positive views towards clinical hypnosis as $38.6 \%$ [7].

We calculated the sample size using an online calculator, at a $99 \%$ confidence interval with the desired precision of the estimate being 0.05 [13]. The calculated sample size was 629 . We received 630 responses. Amongst those who responded, we had to exclude 30 responses as they did not meet our inclusion criteria. Hence, our final sample size was 600 .

\section{Questionnaire development and validation}

Based on our literature search regarding clinical hypnosis and the various myths and misconceptions harboured by the general population, we designed a questionnaire comprising 26 questions [2-4,14-17]. A summary of the questionnaire has been provided below. The details regarding each question and its response have been mentioned in separate tables in the annexure. 


\begin{tabular}{|c|c|c|}
\hline $\begin{array}{l}\text { NUMBER OF } \\
\text { QUESTIONS }\end{array}$ & DOMAIN & $\begin{array}{l}\text { INCLUSION IN ANY SCORE } \\
\text { CALCULATION }\end{array}$ \\
\hline 2 & Sociodemographic data & - \\
\hline 6 & $\begin{array}{l}\text { Awareness regarding the practice of } \\
\text { clinical hypnosis (Table } 1 \text { ) }\end{array}$ & \multirow{2}{*}{$\begin{array}{l}\text { The aggregate of these two } \\
\text { domains was considered as the } \\
\text { awareness score } \\
\text { (Maximum score }=13 \text { ) }\end{array}$} \\
\hline 7 & $\begin{array}{l}\text { Awareness regarding the therapeutic } \\
\text { uses of clinical hypnosis (Table 1) }\end{array}$ & \\
\hline 3 & $\begin{array}{l}\text { Other questions regarding awareness } \\
\text { (Table 1) }\end{array}$ & - \\
\hline 1 & $\begin{array}{l}\text { Initial source of information regarding } \\
\text { clinical hypnosis (Table 3) }\end{array}$ & - \\
\hline 4 & $\begin{array}{l}\text { Attitudes towards clinical hypnosis } \\
\text { (Table } 4 \text { ) }\end{array}$ & $\begin{array}{l}\text { Three out of these four questions } \\
\text { were considered in the attitude } \\
\text { score (Maximum score }=3 \text { ) }\end{array}$ \\
\hline 2 & Additional questions (Table 7) & - \\
\hline $\begin{array}{c}1 \\
\text { (9 sub-questions) }\end{array}$ & $\begin{array}{c}\text { Experience of hypnotherapy (For those } \\
\text { subjects who had visited a } \\
\text { hypnotherapist before) (Table 8) }\end{array}$ & - \\
\hline
\end{tabular}

We used a self-designed pre-validated questionnaire as our primary objective was to perform a preliminary assessment of the awareness and attitudes about clinical hypnosis in an Indian population, without evaluating practical factors such as hypnotisability of the subjects. Pre-validated questionnaires and scales that have been published previously did not satisfy this objective entirely. The questionnaire was validated by ten people including medical professionals like psychiatrists and also members of the general population. We designed the questionnaire and the accompanying informed consent document in English, Hindi and Marathi. A snowball non-random sampling approach was used to reach a large and diverse population. The questionnaire was sent as a Google form link via social media (WhatsApp $\odot$, Facebook $\odot$ ) and email to the subjects, including students at various colleges within the state of Maharashtra, and other professionals. Upon opening the Google form link, the subjects completed a click-through form which mentioned that the subject should live in the state of Maharashtra. After this, they proceeded directly to complete the questionnaire. After completion of the questionnaire, the subjects were requested to share the google form link to two more people above the age of 18 years living within the state of Maharashtra.

\section{Data analysis}

We performed descriptive statistics including frequencies, percentages, and chi-square analysis using IBM SPSS 16.0.

\section{RESULTS}

\section{Sociodemographic Data}

Amongst the total sample of 600 subjects, $58.87 \%$ were females, $38.5 \%$ were males and $2.67 \%$ preferred not to mention their gender. The age of the subjects ranged from 18 years to 77 years, the mean age being 23.13 years.

\section{Awareness about clinical hypnosis (Table 1)}

Calculation of awareness score (As mentioned in the Methodology section). We grouped the subjects into four categories based on their awareness score. (Table 2)

Awareness score distribution. (Figure 1) No subject answered all thirteen questions correctly, with the maximum score being twelve. The Mean awareness score was $45.53 \%$, with a standard deviation of $18.61 \%$. Some questions regarding awareness which need to be mentioned separately are as follows - 
- Only $40 \%$ of subjects had heard about clinical hypnosis

- Only $9 \%$ of subjects were aware of hypnotherapists in their area

- The major misconceptions regarding clinical hypnosis that are evident in our survey are:

1. One might get stuck in the state of hypnosis if something goes wrong, which only $35.17 \%$ of subjects believed to be false

2. When in the hypnotized state, one might reveal a secret that they are not willing to, which only $11.33 \%$ of subjects believed to be false

Differences in awareness concerning gender: A chi-square test was performed to compare the awareness scores of males and females (chi-square $=4.332, \mathrm{p}=0.632$ ). The test depicted that there was no statistically significant difference in the awareness scores of males and females.

Sources of information: The most common sources of information regarding hypnosis reported by our subjects were movies/television (68.17\%) and magic shows/stage hypnosis (29.5\%). (Table 3). Further, we assessed the association of awareness with the two most common sources of information in our studymovies and magic shows/stage hypnosis.

A chi-square test performed to compare the awareness scores of subjects reporting movies as a source of information versus those not reporting movies as a source of information (chi-square $=1.032 . p=0.794$ ) depicted no statistically significant difference in the awareness scores. A chi-square test performed to compare the awareness scores of subjects reporting magic shows/stage hypnosis as a source of information versus those not reporting magic shows/stage hypnosis as a source of information (chi-square $=1.032 . \mathrm{p}=$ 0.794) depicted no statistically significant difference in the awareness scores.

\section{Attitudes towards clinical hypnosis (Table 4)}

Calculation of attitude score: (As mentioned in the Methodology section). We grouped the subjects into four categories based on their attitude score.

Attitude score distribution (Figure 2): The mean attitude score was 1.8 out a maximum attainable score of three, with a standard deviation of $0.926 .66 .2 \%$ of the subjects showed positive attitudes towards clinical hypnosis, considering that the categories "likely" and "very likely" represent positive attitudes since they include attitude scores over $50 \%$. This shows an overall positive attitude amongst the subjects towards clinical hypnosis. Our survey also revealed that $71.4 \%$ males showed positive attitudes, while $63.7 \%$ females showed positive attitudes, though the difference was insignificant according to the chi-Square test (chiSquare $=12.552 ; p=0.051$ ). Significant questions regarding attitudes which need to be mentioned separately are as follows-

1. $82.5 \%$ of the surveyed population reported some likelihood to try hypnosis as a complementary form of treatment under a trained professional.

2. However, only $35 \%$ of the sample was willing to try self-hypnosis.

3. Only $62 \%$ of the population was willing to accept clinical hypnosis as a field if proof of its use is provided to them.

Association of awareness about clinical hypnosis with attitudes towards it (Table 6): Based on the chisquare analysis of the comparison between awareness scores and attitude scores, we found that amongst the $15.5 \%$ subjects with good awareness, $76.4 \%$ were very likely or likely to accept clinical hypnosis. Further, $57.2 \%$ of subjects with very poor awareness were reluctant to accept clinical hypnosis. An increase in awareness score correlated with an increase in attitude score (chi-square $=48.561^{\prime} \mathrm{p}=0.0001$ ). This was also evidenced by the values of unstandardized residuals in the chi-square table described above. A positive residual value represents an excess of frequency in a particular cell of the table as compared to the expected value of frequency in that cell, whereas a negative value represents a deficit. Some important residual values are mentioned below: 
1. In the not at all likely group: +9 in the poor awareness category and -10.2 in moderate

2. In the hesitant group: +14 in the very poor awareness group

3. In the likely group: -9.2 in the very poor awareness group

4. In the very likely group: -8.7 in the very poor awareness group, -12.5 in the poor awareness group, +15.4 in the good awareness group

\section{Association of awareness with attitudes - comparison of individual questions}

$82.5 \%$ of subjects were likely to accept clinical hypnosis as a supplementary form of treatment. A chi-square test comparing the likelihood of accepting clinical hypnosis as a supplementary treatment between the subjects who believed it to be a normal and natural state of mind versus those who did not believe so was statistically significant (chi-square $=8.430, \mathrm{p}=0.004$ ).

$58.8 \%$ of the subjects who were likely to accept clinical hypnosis as a supplementary treatment believed that there is scientific evidence to prove its use, whereas $41.9 \%$ of the subjects who were not at all likely to accept clinical hypnosis believed that there is scientific evidence to prove its usefulness. A chi-square test comparing the likelihood of accepting clinical hypnosis as a supplementary treatment between the subjects who believed in the existence of scientific evidence versus those who did not was statistically significant (chi-square $=$ $10.013, p=0.002$ ). Subjects who believed in the existence of scientific evidence also depicted more positive attitudes towards clinical hypnosis (chi-square $=14.093, \mathrm{p}=0.003$ ).

Additional questions (Table 7): We asked two questions about the perceptions of the subjects regarding clinical hypnosis, which did not relate directly to their awareness or attitudes.

Experience of clinical hypnosis (Table 8): Out of the 600 subjects in our survey, only five stated that they had visited a hypnotherapist before. The sources that suggested a visit to the hypnotherapist included friends, physicians and psychiatrists. Most subjects reported that they felt nervous before undergoing hypnosis, and few felt some discomfort or foggy sensation after their session. Four out of the five subjects found clinical hypnosis beneficial for their respective indications while three of the above four subjects said that they would be willing to approach a hypnotherapist again and refer people to hypnotherapists. Clinical variables influencing severity of the alcohol dependence such as duration of alcohol intake, mean SADQ score, comorbid substance abuse and family history of alcohol dependence did not differ significantly between the two groups. But there were some significant differences in terms of certain clinical variables which may have influenced the results and this has been looked at under the discussion part of the paper. [Table 2]

\section{DISCUSSION}

From the results of our state-wide survey, we found that the overall attitudes of the subjects towards clinical hypnosis were positive. Very few subjects were aware of hypnotherapists in their area, suggesting either an imbalance in the sample to hypnotherapist ratio or a lack of awareness of the same. The awareness scores revealed certain misconceptions prevalent in a majority of our sample, including the fear of getting stuck in hypnosis, losing control under hypnosis and revelation of secrets involuntarily while in hypnosis. These apprehensions highlight the importance of educating the population regarding clinical hypnosis, providing them with accurate information, filtering the sources of information and providing scientific backing to the information being communicated to the people. This may be achieved by addressing these misconceptions via certified training programs for medical professionals and sensitisation programmes for the public.

While comparing the awareness scores concerning the gender distribution of the sample, we found that no statistically significant relationship occurred between awareness scores and gender. However, previous studies have shown that the perceptions of people about clinical hypnosis may vary with gender, with females being less likely than males to associate hypnosis with mental instability [9]. However, another article mentioned that there was little information on gender or age-group related differences in the views or attitudes regarding clinical hypnosis, which we found to be in line with our study [15]. Thus, similarities in the attitudes and awareness regarding clinical hypnosis in both genders indicate that both need to be addressed equally while taking steps to improve awareness. 
Literature suggests that the sources of information regarding clinical hypnosis can influence the perceptions of people towards clinical hypnosis. Hollywood's portrayal of hypnosis involving a "Svengali-like" fi gure exerting complete control over a passive and compliant subject is likely to lead to common misconceptions and negative attitudes towards clinical hypnosis, and may also undermine the public's confi dence in the clinical utility of hypnosis [14]. It had been observed that patients who obtained their knowledge from newspapers, books and television were more likely to request further information about clinical hypnosis than those patients who obtained information via stage hypnosis or from other people [18]. They also reported that patients who procured information about hypnosis mainly through television or stage shows held unfavourable views about clinical hypnosis. However, we did not observe any differences in the awareness or attitudes of subjects concerning their sources of information.

Since we identified that movies, television and magic shows were the chief sources of information regarding hypnosis amongst our subjects, we believe that there is a need for an accurate representation of clinical hypnosis through these media. This will help reach out to most of the population, while simultaneously reducing the prevalence of popular myths.

The overall positive attitude amongst the subjects may be directly associated with better outcomes of clinical hypnosis in them, as is suggested experimentally that the manipulation of a subject's attitude can significantly affect the level of hypnotisability [18]. A positive attitude increases hypnotisability and predisposes an individual toward a satisfactory hypnotherapeutic experience [18]. A positive attitude may also increase the likelihood of accepting clinical hypnosis in the future. Furthermore, over $80 \%$ of the population that we surveyed showed some likelihood to try hypnosis as a complementary form of treatment under a trained professional indicating a widespread acceptance of clinical hypnosis. However, less than half of the sample was willing to try self-hypnosis. This may be attributed to a lack of complete knowledge regarding the procedures or the effectiveness of self-hypnosis.

On comparing the awareness and attitudes we found that amongst the subjects with good awareness, the majority were very likely or likely to accept clinical hypnosis, highlighting the importance of spreading accurate and scientifically backed information to the people to improve their awareness.

Analysis of some individual questions revealed that the correct perception that hypnosis is a normal and natural state of mind seems to have a significant impact on the acceptance of hypnosis as a supplementary treatment as was evidenced by greater acceptability amongst those who considered it so. Furthermore, we found a statistically significant association between acceptance of clinical hypnosis and the perception of it having scientific evidence, which suggests that dissemination of such information can help promote clinical hypnosis amongst the people.

\section{Limitations}

Because of the lack of availability of adequate literature on the prevalence of awareness in the Indian population, we could not calculate a sample size specifically for the Indian scenario. We did not obtain a detailed socio-demographic profile of the subjects as it was not amongst the primary objectives of this study. Since we circulated the questionnaire online, we were unable to target the segment of the population who were unable to use an electronic device. More detailed statistical analysis using ANOVA and structural equations could have been performed.

For future studies, a particular target population with a detailed socio-demographic profile may be defined for assessing the awareness and attitudes in specific population groups. Analysis based on these parameters may reveal significant relationships.

\section{CONCLUSION}

One of the best ways to improve the attitudes of a population towards an idea is to generate more awareness regarding the same. Thus, it is important is to improve awareness regarding the practice of clinical hypnosis in Indian society, which would then manifest as an increase in the overall positive attitude of people. Improving the awareness and increasing the credibility of information provided to the public by improving and monitoring both, the sources of information, as well as the scientific basis of disseminated information, will also improve the overall perception. Coupled with this is the need to provide more options for reliable 
and efficient clinical hypnosis services at various levels of healthcare, which would give the public the option of utilising clinical hypnosis effectively.

\section{ANNEXURE - TABLE 1}

\begin{tabular}{|c|c|c|c|}
\hline Practice of hypnosis & Yes & No & Uncertain \\
\hline $\begin{array}{l}\text { 1. Hypnosis is a normal and natural state of mind } \\
\text { where we are more prone to suggestions }\end{array}$ & (Correct) & & \\
\hline 2. It is a state similar to meditation & (Correct) & & \\
\hline 3. It is a state similar to unconsciousness & & (Correct) & \\
\hline 4. It is a form of communication using suggestions & (Correct) & & \\
\hline 5. Are you aware of any Hypnotherapists in your area & $\begin{array}{l}\text { (Regarded as } \\
\text { correct) }\end{array}$ & & \\
\hline $\begin{array}{l}\text { 6. Who do you think can practice hypnosis? (Multiple } \\
\text { options) (Both correct }=+1 \text {; either one correct = } \\
+0.5 \text {; any incorrect option mentioned }=0 \text { ) }\end{array}$ & \multicolumn{3}{|c|}{$\begin{array}{l}\text { A) Psychiatrists (Correct) } \\
\text { B) General physicians } \\
\text { C) Hypno-therapists (Correct) } \\
\text { D) Other trained professionals }\end{array}$} \\
\hline \multicolumn{4}{|l|}{ Therapeutic uses of hypnosis } \\
\hline 1. Have you heard about clinical hypnosis & $\begin{array}{l}\text { (Regarded as } \\
\text { correct) }\end{array}$ & & \\
\hline $\begin{array}{l}\text { 2. It is a non-invasive therapy complementary to } \\
\text { conventional medicine }\end{array}$ & (Correct) & & \\
\hline 3. Hypnotherapy has scientific evidence to prove its use & (Correct) & & \\
\hline $\begin{array}{l}\text { 4. One might get stuck in the state of hypnosis if } \\
\text { something goes wrong }\end{array}$ & & (Correct) & \\
\hline $\begin{array}{l}\text { 5. Through hypnosis, a disease can be cured in one } \\
\text { session }\end{array}$ & & (Correct) & \\
\hline $\begin{array}{l}\text { 6. When in the hypnotic state, one might reveal a } \\
\text { secret they are not willing to }\end{array}$ & & (Correct) & \\
\hline 7. It can be used to recall long-forgotten memories. & (Correct) & & \\
\hline \multicolumn{4}{|l|}{ Other questions (Not included in the awareness score) } \\
\hline $\begin{array}{l}\text { 1. It is a very time-consuming process } \\
\text { 2. Hypnotherapy is a comparatively costly treatment } \\
\text { 3. Hypnosis has long term effects }\end{array}$ & & & \\
\hline
\end{tabular}

${ }^{*}$ Questions regarding the awareness of the subjects about clinical hypnosis

Table 2

\begin{tabular}{|c|c|c|c|}
\hline Awareness category & Score range (out of 13) & Number of subjects & Percentage of subjects \\
\hline Very Poor & $0-3$ & 77 & 12.8 \\
\hline Poor & $3-6$ & 257 & 42.8 \\
\hline Moderate & $6-8$ & 173 & 28.8 \\
\hline Good & $8-13$ & 93 & 15.5 \\
\hline
\end{tabular}

${ }^{*}$ Categorization of the subjects based on their awareness scores 
Table 3

\begin{tabular}{|l|c|}
\hline Question- Where were you initially introduced to hypnosis? (Multiple choices) & $\%$ \\
\hline Movie/TV & 68.17 \\
\hline Magic shows (stage hypnosis) & 29.5 \\
\hline Newspaper & 5.5 \\
\hline Friend/Relative/Associate (who have undergone hypnosis) & 11 \\
\hline Internet & 19.67 \\
\hline Don't know & 5.83 \\
\hline Other & 2.33 \\
\hline
\end{tabular}

*Question asked about the source of information through which the subject was initially introduced to clinical hypnosis. More than one option could be chosen

Table 4

\begin{tabular}{|c|c|c|c|}
\hline Included in the attitude score & \multicolumn{3}{|c|}{ Responses } \\
\hline $\begin{array}{l}\text { 1. How comfortable will you be accepting } \\
\text { hypnosis as a supplementary treatment } \\
\text { under the supervision of a trained } \\
\text { professional? }\end{array}$ & \multicolumn{3}{|c|}{$\begin{array}{l}\text { A) Extremely likely } \\
\text { B) Very likely } \\
\text { C) Moderately likely } \\
\text { D) Not at all likely }\end{array}$} \\
\hline \multicolumn{4}{|c|}{$\begin{array}{l}\text { (Extremely likely, very likely and moderately likely; each was given a score of } 1 \text { in the attitude scor } \\
\text { Not at all likely was given a score of } 0 \text { ) }\end{array}$} \\
\hline $\begin{array}{l}\text { 2. Self-hypnosis or auto-hypnosis is a form, } \\
\text { process or result of hypnosis which is self- } \\
\text { induced, and normally makes use of self- } \\
\text { suggestion. Would you most likely try self- } \\
\text { hypnosis? }\end{array}$ & Yes & No & Uncertain \\
\hline $\begin{array}{l}\text { 3. Like psychiatry and psychology, if proven } \\
\text { to be useful, will you accept hypnotherapy } \\
\text { as a field in itself? }\end{array}$ & Yes & No & Uncertain \\
\hline \multicolumn{4}{|l|}{ Not included in the attitude score } \\
\hline $\begin{array}{l}\text { 4. While undergoing hypnosis as a treatment } \\
\text { what will your apprehensions be? } \\
\text { (Multiple options could be chosen) }\end{array}$ & \multicolumn{3}{|c|}{$\begin{array}{l}\text { A). I might forget things that I remember } \\
\text { normally (Amnesia) } \\
\text { B) I might reveal things that I don't want to } \\
\text { C) I might not be able to concentrate on } \\
\text { routine activities } \\
\text { D) I won't be able to come out of hypnosis }\end{array}$} \\
\hline
\end{tabular}

${ }^{*}$ Questions regarding the attitudes of the subjects towards clinical hypnosis

Table 5

\begin{tabular}{|c|c|c|c|}
\hline Attitude Category & Corresponding Scores & Frequency & Percentage \\
\hline Not at all & 0 & 63 & $10.5 \%$ \\
\hline Hesitant & 1 & 140 & $23.3 \%$ \\
\hline Likely & 2 & 251 & $41.8 \%$ \\
\hline Very Likely & 3 & 146 & $24.3 \%$ \\
\hline
\end{tabular}

*Categorization of the subjects into 4 groups based on their attitude scores 
Table 6

\begin{tabular}{|c|c|c|c|c|c|c|c|}
\hline & \multicolumn{5}{|c|}{ Awareness category } \\
\hline & & & Very poor & Poor & Moderate & Good & Total \\
\hline \multirow{8}{*}{$\begin{array}{l}\text { Attitude } \\
\text { category }\end{array}$} & Not at all & Frequency & 12 & 36 & 8 & 7 & 63 \\
\hline & & Residual & 3.9 & 9.0 & -10.2 & -2.8 & \\
\hline & Hesitant & Frequency & 32 & 59 & 34 & 15 & 140 \\
\hline & & Residual & 14.0 & -1.0 & -6.4 & -6.7 & \\
\hline & Likely & Frequency & 23 & 112 & 83 & 33 & 251 \\
\hline & & Residual & -9.2 & 4.5 & 10.6 & -5.9 & \\
\hline & Very likely & Frequency & 10 & 50 & 48 & 38 & 146 \\
\hline & & Residual & -8.7 & -12.5 & 5.9 & 15.4 & \\
\hline Total & Frequency & & 77 & 257 & 173 & 93 & 600 \\
\hline
\end{tabular}

${ }^{*}$ Chi-square test performed to evaluate the association between awareness scores and attitude scores of the subjects

Table 7

1. Do you think there is a stigma associated with Hypnotherapy in society?

2. Why would you be hesitant to use hypnotherapy? (Multiple options could be chosen)

A) Fear of being judged by society

B) Lack of faith in the hypnotherapist

C) Unaware about the procedure

D) Bad experience with another hypnotherapist

${ }^{*}$ Questions within the questionnaire that did not pertain to the awareness and attitudes of the subjects

Table 8

\begin{tabular}{|l|l|}
\hline $\begin{array}{l}\text { Have you been to a } \\
\text { hypnotherapist before? }\end{array}$ & \multicolumn{1}{c|}{$\begin{array}{c}\text { Yes } \\
\text { No }\end{array}$} \\
\hline If yes (Answer to the question above), \\
1. What was the reason? \\
2. Who recommended the hypnotherapist \\
3. How many sessions did you take \\
4. Did you experience any dizziness or discomfort after the session? Please specify in case of any \\
other post hypnotic experience. \\
5. Were you nervous about it initially? \\
6. Did it prove to be helpful? \\
7. During hypnosis, were you aware of your actions? \\
8. Would you go to a hypnotherapist again? \\
9. Will you recommend hypnotherapy to other people? \\
These 9 questions were subjective in nature, where the subjects had to fill their answers in a blank \\
space provided
\end{tabular}

${ }^{*}$ Questions regarding prior experience with clinical hypnosis 
Annexure 2: Figures

Figure 1

Histogram with frequency polygon depicting the distribution of the awareness score of the subjects

Mean $=5.92$

$\mathrm{SD}=2.42$

Total questions $=13$

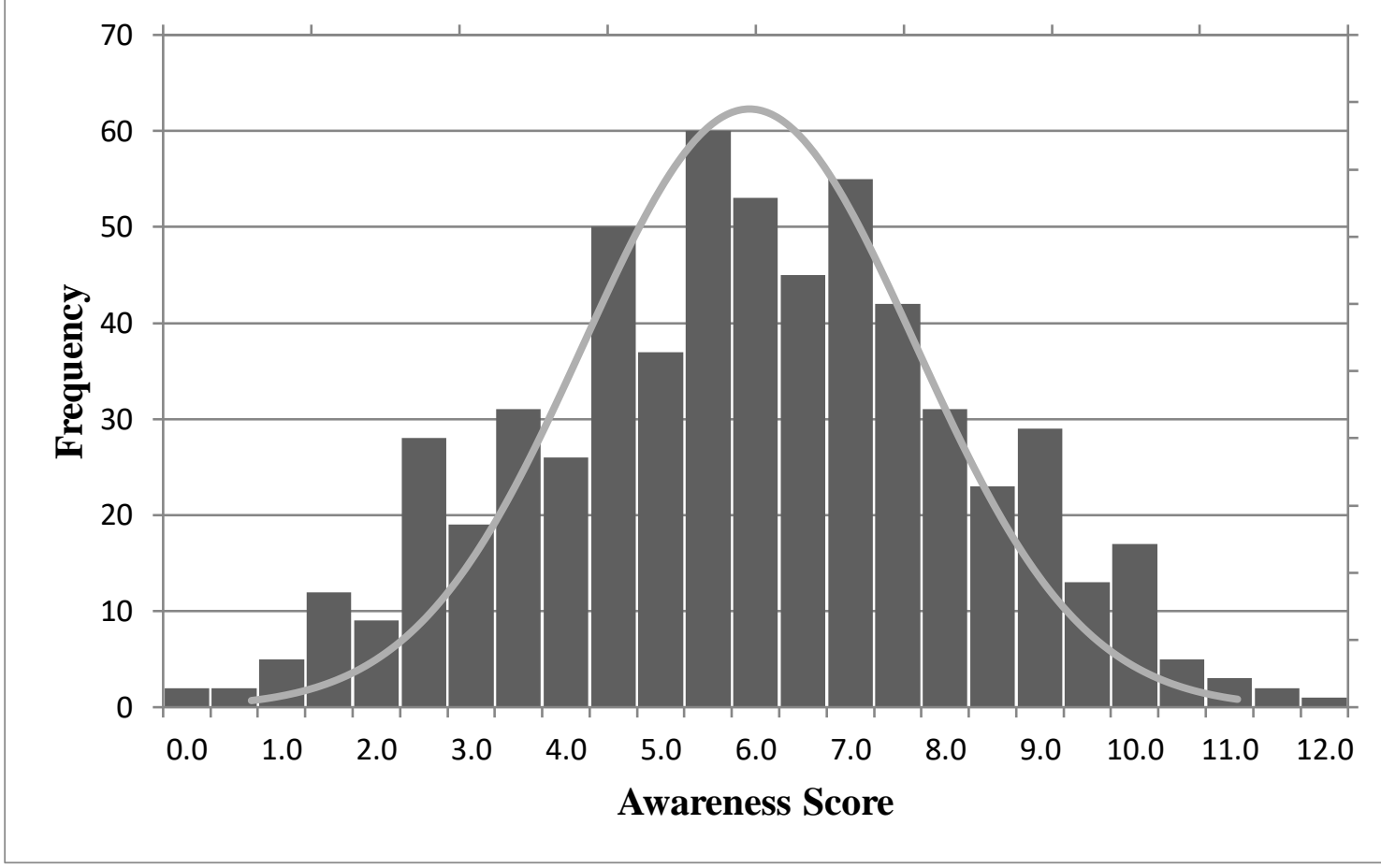

Maximum score $=12$

Minimum score $=0$

\section{Figure 2}

Bar chart depicting the distribution of the subjects across the four attitude categories

1. Not at all likely to accept clinical hypnosis

2. Hesitant to accept clinical hypnosis

3. Likely to accept clinical hypnosis

4. Very likely to accept clinical hypnosis (Also refer to table 5)

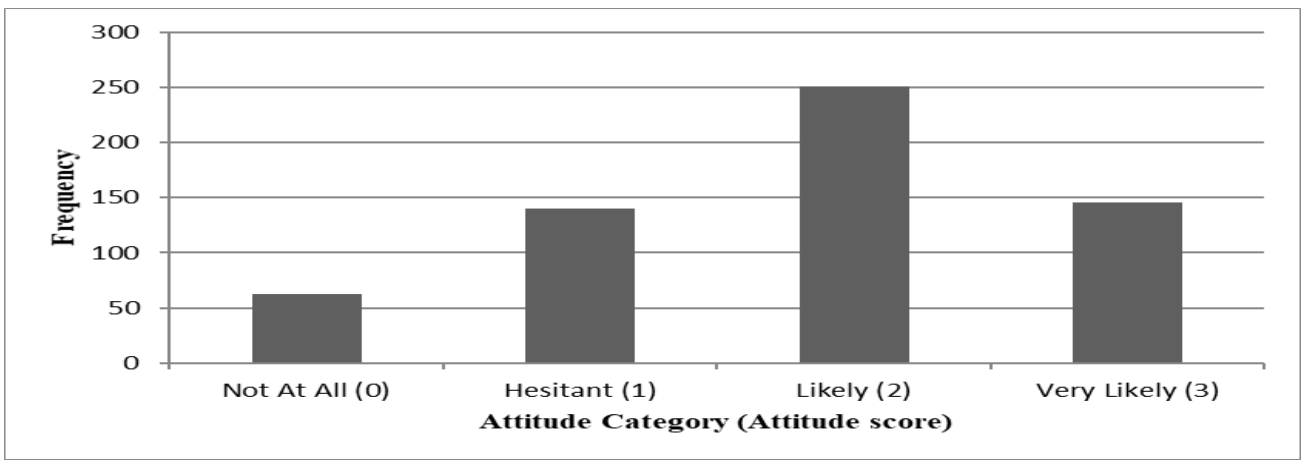


Mean $=1.8, \mathrm{SD}=0.926$, Total questions $=3$, Maximum score $=3$, Minimum score $=0$

\section{REFERENCES}

1. Elkins GR, Barabasz AF, Council JR, Spiegel D. Advancing research and practice: the revised APA Division 30 definition of hypnosis. Int J Clin Exp Hypn 2015;63(1):1-9.

2. Gonsalkorale WM, Miller V, Afzal A, Whorwell PJ. Long term benefits of hypnotherapy for irritable bowel syndrome. Gut 2003;52(11):1623-9.

3. Hammond DC. Review of the Efficacy of Clinical Hypnosis with Headaches and Migraines. Int J Clin Exp Hypn 2007;55(2):207-19.

4. Allison N. Hypnosis in modern dentistry: Challenging misconceptions. FDJ 2015;6(4):172-5.

5. Häuser W, Hagl M, Schmierer A, Hansen E. The Efficacy, Safety and Applications of Medical Hypnosis. Dtsch Arztebl Int 2016;113(17):289-96.

6. Sharma VK, Pandya P, Kumar R, Gupta G. Evaluation of hypnotherapy in pain management of cancer patients: A clinical trial from India. Indian J Pain 2017;31(2):100.

7. Palsson $\mathrm{O}$, Twist $\mathrm{S}$, Walker $\mathrm{M}$. A national survey of clinical hypnosis views and experiences of the adult population in the United States. Int J Clin Exp Hypn 2019;67(4):428-48.

8. Channon LD. Some Preconceptions about Hypnosis among Preclinical Medical students: A Brief Communication. Int J Clin Exp Hypn 1984; 32(4):356-361.

9. Green JP, Page RA, Rasekhy R, Johnson LK, Bernhardt SE. Cultural Views and Attitudes about Hypnosis: A Survey of College Students Across Four Countries. Int J Clin Exp Hypn 2006;54(3):263-80.

10. Krouwel M, Jolly K, Greenfield S. What the public think about hypnosis and hypnotherapy: A narrative review of literature covering opinions and attitudes of the general public 1996-2016. Complement Ther Med 2017;32:75-84.

11. Kleinhauz M, Beran B. Misuse of Hypnosis: A Factor in Psychopathology. Am J Clin Hypn 1984;26(4):283-90.

12. Getzlaf SB, Cross HJ. Hypnotists' associations: a consumer's confusion. Int J Clin Exp Hypn 1988;36(4):262-74.

13. Epitools [Internet]. [cited 2020 Jun 12]. Available from: https://epitools.ausvet.com.au/oneproportion

14. Green JP. Beliefs About Hypnosis: Popular Beliefs, Misconceptions, and the Importance of Experience. Int J Clin Exp Hypn 2003;51(4):369-81.

15. Eisen MR. Return of the repressed: hypnoanalysis of a case of total amnesia. Int J Clin Exp Hypn 1989;37(2):107-19.

16. Cheek DB. An indirect method of discovering primary traumatic experiences: two case examples. Am J Clin Hypn 1989;32(1):41-7.

17. Williamson A. What is hypnosis and how might it work? Palliat Care. 2019;12:1-4.

18. McIntosh IB, Hawney M. Patient attitudes to hypnotherapy in a general medical practice: a brief communication. Int J Clin Exp Hypn 1983;31(4):219-23.

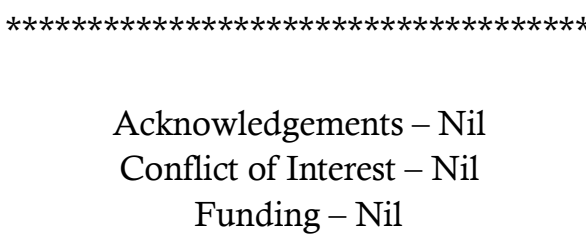

